\title{
Calculations for a BWR Lattice with Adjacent Gadolinium Pins Using the Monte Carlo Cell Code Serpent v.1.1.7
}

\author{
Diego Ferraro and Eduardo Villarino \\ Nuclear Engineering Department, INVAP S.E., Comandante Luis Piedrabuena 4950, San Carlos de Bariloche, \\ Río Negro R8403CPV, Argentina \\ Correspondence should be addressed to Diego Ferraro, dferraro@invap.com.ar
}

Received 30 August 2010; Accepted 26 November 2010

Academic Editor: Juan Ferreri

Copyright ( 2011 D. Ferraro and E. Villarino. This is an open access article distributed under the Creative Commons Attribution License, which permits unrestricted use, distribution, and reproduction in any medium, provided the original work is properly cited.

\begin{abstract}
Monte Carlo neutron transport codes are usually used to perform criticality calculations and to solve shielding problems due to their capability to model complex systems without major approximations. However, these codes demand high computational resources. The improvement in computer capabilities leads to several new applications of Monte Carlo neutron transport codes. An interesting one is to use this method to perform cell-level fuel assembly calculations in order to obtain few group constants to be used on core calculations. In the present work the VTT recently developed Serpent v.1.1.7 cell-oriented neutronic calculation code is used to perform cell calculations of a theoretical BWR lattice benchmark with burnable poisons, and the main results are compared to reported ones and with calculations performed with Condor v.2.61, the INVAP's neutronic collision probability cell code.
\end{abstract}

\section{Introduction}

The Monte Carlo method is traditionally used in neutronic calculations to solve criticality and shielding problems due to its capability to model complicated geometries and its quasicontinuous energy treatment. However its high computational requirements had restricted its applications to other areas in neutronic calculations. With the advance in computer performance the use of this method to perform cell calculations to obtain few group constants arises as a very promising future application. This application is even more interesting when few group constants are needed to core calculations involving high heterogeneous $3 \mathrm{D}$ devices, such as irradiations facilities.

The Serpent code [1] is a new Monte Carlo continuousenergy neutron transport code developed in the VTT Technical Research Centre of Finland oriented to pin cell calculations with the capability of burnup and few group constants generation. Nowadays this code is oriented to pintype assembly calculations, but it has the capability to model more general 3D geometries, which makes it an interesting option to obtain few group constants in complicated devices on a reactor core.
In the present work a well-known BWR lattice benchmark calculation [2] is performed using Serpent code and nuclear data from ENDF/B-VI.8. The main results are compared with reported values and with calculations performed with the INVAP's collision probability code Condor [3] using nuclear data from WIMS library (69 groups) [4] and WLUP library (172 groups) [5].

\section{Models}

The fuel element with adjacent poisoned pins with Gadolinium reported on the theoretical benchmark [2] was modeled in Serpent and Condor codes. This fuel element consists of a $4 \times 4$ pin assembly with two Gadolinium poisoned pins. The main characteristics are listed on Table 1.

The models developed in Condor (using Collision probabilities 2D) and Serpent (using Monte Carlo 2D) are shown on Figures 1(a) and 1(b), respectively.

As it can be seen, the Gd pins were divided into four zones in both models. In addition all the pins were divided in four zones on Serpent model. Regarding burnup calculations, the Condor model evolves each zone individually, while the developed Serpent model only differs in the evolution for 


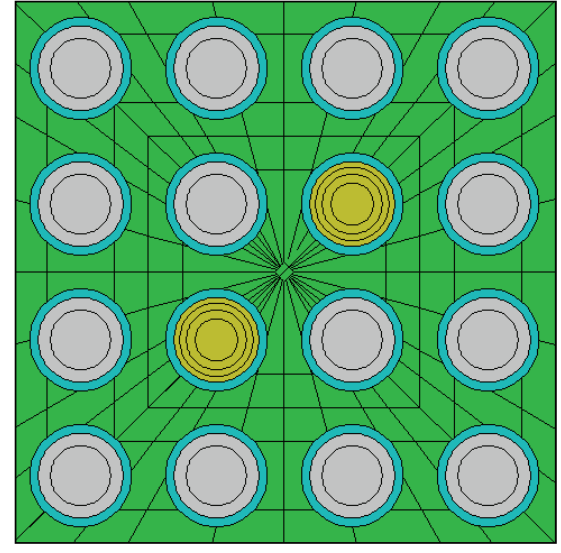

(a)

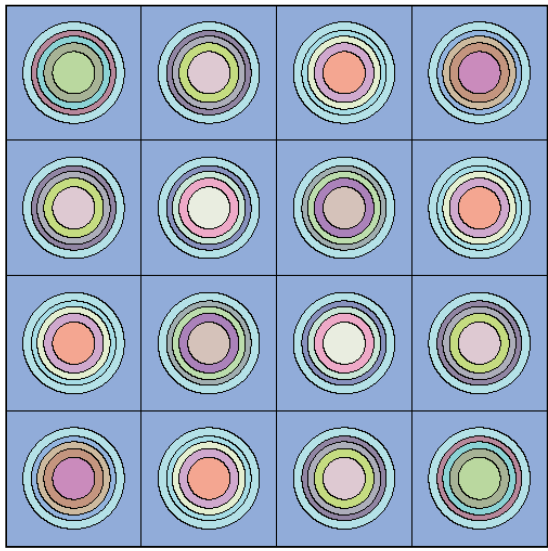

(b)

Figure 1: Models developed for BWR cluster (a) Condor v 2.61 (b) Serpent v. 1.1.7.

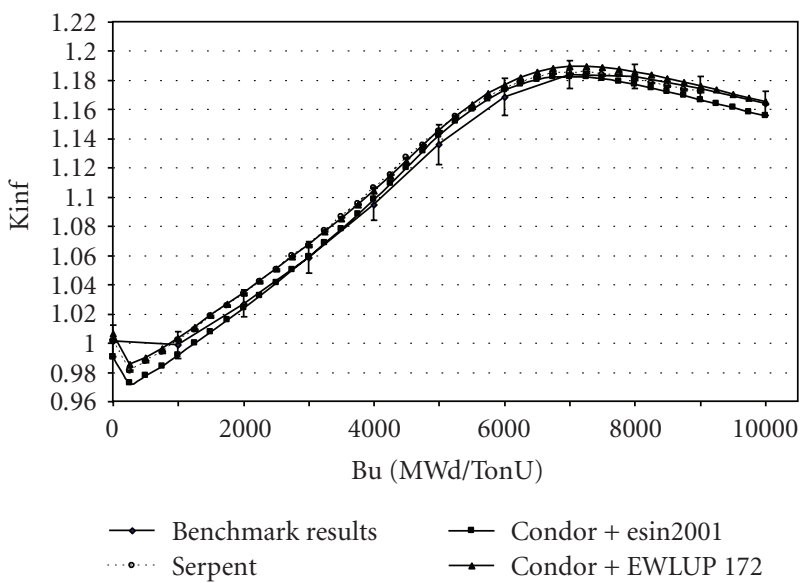

FIGURE 2: Burnup results for both models.

the two types of fuel pin. The Condor model was run using nuclear data from esin2001 [4] library (based on WIMS69) and WLUP library [5] (172 groups). Serpent model was run using nuclear data from ENDF/B-VI.8 in ACE format. Both Condor and Serpent burnup calculations used the predictor-corrector method. Condor burnup calculations evolved the isotopes included on the burnup chain defined on each library used. In Serpent code the decay and fission data is obtained directly from the ENDF/B-VI.8 library, but inventory report was demanded for 70 isotopes.

\section{Results Comparison}

Results were obtained for both models. The running time (sequential, notparallel mode) involved on Serpent calculations reached $435 \mathrm{~min}$ on a $2 \mathrm{Ghz} \mathrm{CPU}$, while the calculations performed on Condor code required 4 minutes for esin 2001 library and $10 \mathrm{~min}$ for EWLUP 172 for the same CPU.

Results regarding infinite multiplication factors, main isotope evolution, and flux profiles were compared. Table 2
TABle 1: Problem specification.

\begin{tabular}{lc}
\hline \multicolumn{2}{c}{ Fuel } \\
\hline Material & $\mathrm{UO}_{2}$ \\
Density & $10 \mathrm{~g} / \mathrm{cm}^{3}$ \\
Temperature & $600^{\circ} \mathrm{C}$ \\
U-235 enrichment & $3 \% \mathrm{wt}$ \\
Diameter & $1 \mathrm{~cm}$ \\
Gd-pin poison & $\mathrm{Gd}_{2} \mathrm{O}_{3}$ \\
Poison percentage on Gd-Pin & $3 \% \mathrm{wt}$ \\
Average power density & $20 \mathrm{~W} / \mathrm{g}$ \\
\hline \multicolumn{2}{c}{ Clad } \\
\hline Material & $\mathrm{Zircaloy}-2$ \\
Density & $6.55 \mathrm{~g} / \mathrm{cm}^{3}$ \\
Temperature & $300^{\circ} \mathrm{C}$ \\
Inner diameter & $1 \mathrm{~cm}$ \\
Outer diameter & $1.2 \mathrm{~cm}$ \\
\hline & \\
\hline Material & $\mathrm{H}_{2} \mathrm{O}$ \\
Void & $0 \%$ \\
Condition & Moderator \\
Lattice pitch & \\
\hline
\end{tabular}

shows the results for the infinite multiplication factor for fresh/hot/clean condition. Serpent result includes the statistical convergence.

In addition, results for burnup evolution for both models and those reported on the benchmark are shown on Figure 2.

As it can be seen from Table 2 and Figure 2 a good agreement exist between both codes and benchmark results. Furthermore, reactivity results obtained with Serpent have a better agreement with those obtained with Condor + EWLUP 172 due to the fact that nuclear data sets are similar.

Another comparison regarding isotope burnup was performed. The evolution for ${ }^{235} \mathrm{U},{ }^{239} \mathrm{Pu}$, and ${ }^{155} \mathrm{Gd}$ in the poisoned pin are shown on Figures 3, 4, and 5, respectively. 
TABLe 2: Results for Clean/Hot/Fresh condition.

\begin{tabular}{lcccc}
\hline & Serpent & Condor + esin2001 & Condor + EWLUP 172 & Benchmark \\
\hline $\mathrm{k}$ infinite & $1.0016 \pm 0.0007$ & 0.9908 & 1.0062 & $1.0014 \pm 0.011$ \\
\hline
\end{tabular}

TABLE 3: ${ }^{155} \mathrm{Gd}$ Radial distribution at $2000 \mathrm{MWd} /$ tonU in the poisoned pin.

\begin{tabular}{lccccc}
\hline & & \multicolumn{3}{c}{${ }^{155}$ Gd numerical density [at/cmb] } \\
Mean radius $(\mathrm{cm})$ & Benchmark & Benchmark Stdev & Serpent & Condor + esin2001 & Condor + EWLUP 172 \\
\hline 0.125 & $1.29 \mathrm{E}-04$ & $3.4 \mathrm{E}-06$ & $1.28 \mathrm{E}-04$ & $1.28 \mathrm{E}-04$ & $1.29 \mathrm{E}-04$ \\
0.302 & $1.20 \mathrm{E}-04$ & $3.3 \mathrm{E}-06$ & $1.18 \mathrm{E}-04$ & $1.18 \mathrm{E}-04$ & $1.19 \mathrm{E}-04$ \\
0.393 & $9.41 \mathrm{E}-05$ & $3.8 \mathrm{E}-06$ & $9.25 \mathrm{E}-05$ & $9.00 \mathrm{E}-05$ & $9.31 \mathrm{E}-05$ \\
0.467 & $4.95 \mathrm{E}-05$ & $8.6 \mathrm{E}-06$ & $4.71 \mathrm{E}-05$ & $4.26 \mathrm{E}-05$ & $4.60 \mathrm{E}-05$ \\
\hline
\end{tabular}

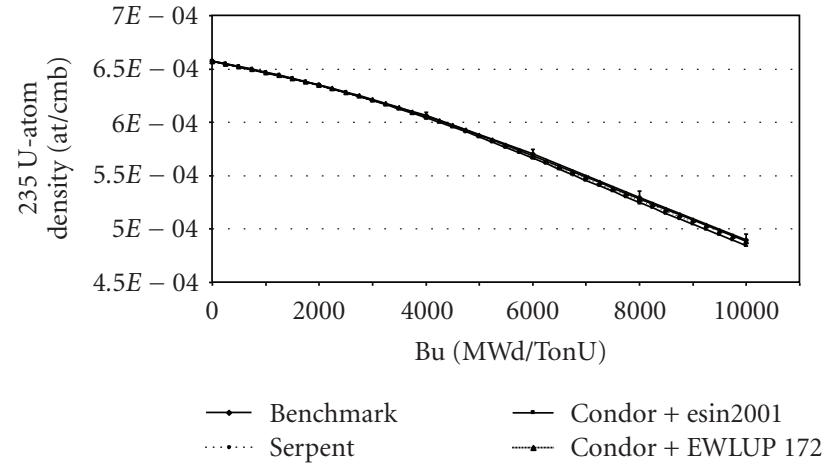

FIgURE 3: ${ }^{235} \mathrm{U}$ burnup in the poisoned pin.

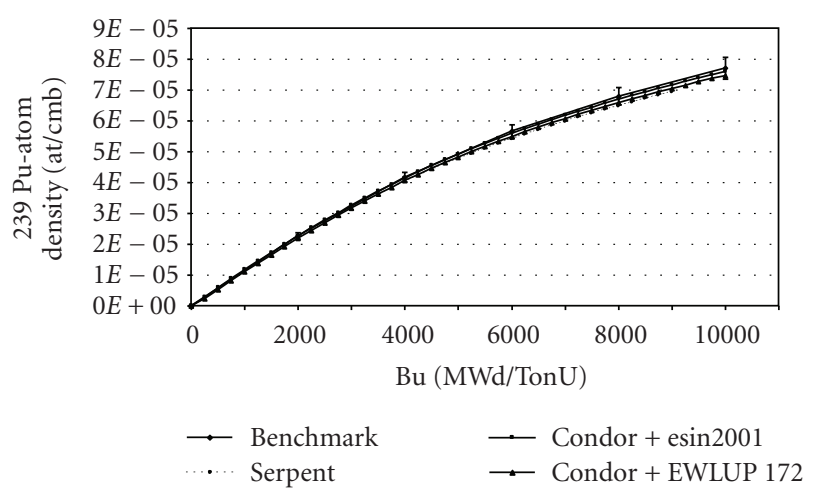

Figure 4: ${ }^{239} \mathrm{Pu}$ in the poisoned pin.

As it can be seen from Figures 3-5 good agreement is obtained in the evolution of the most relevant isotopes for both models.

In addition, the radial distribution for ${ }^{155} \mathrm{Gd}$ in the poisoned pin at $2000 \mathrm{MWd} /$ tonU has been calculated with both models for each radial zone. The results are shown on Table 3.

As it can be seen, the results for radial distribution of ${ }^{155} \mathrm{Gd}$ obtained are consistent between models and reported values.

Finally, the thermal flux profile in the horizontal direction $(x)$ of the fuel assembly is compared for two burnups

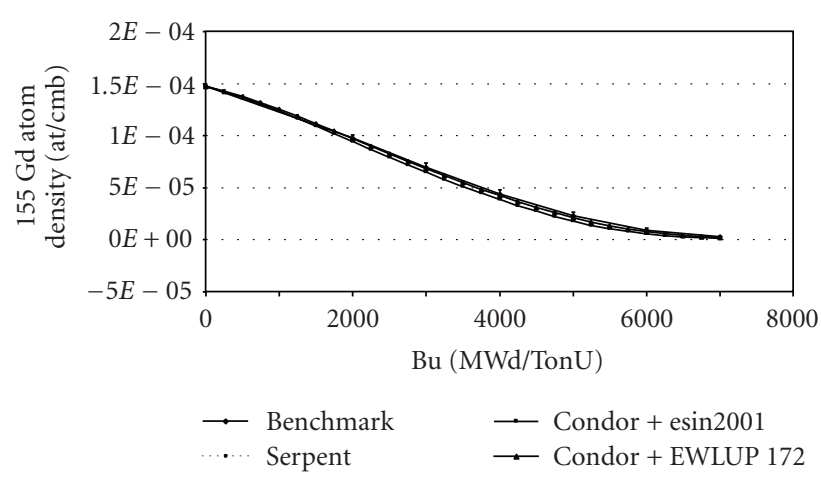

FIgURE 5: ${ }^{155} \mathrm{Gd}$ burnup in the poisoned pin.

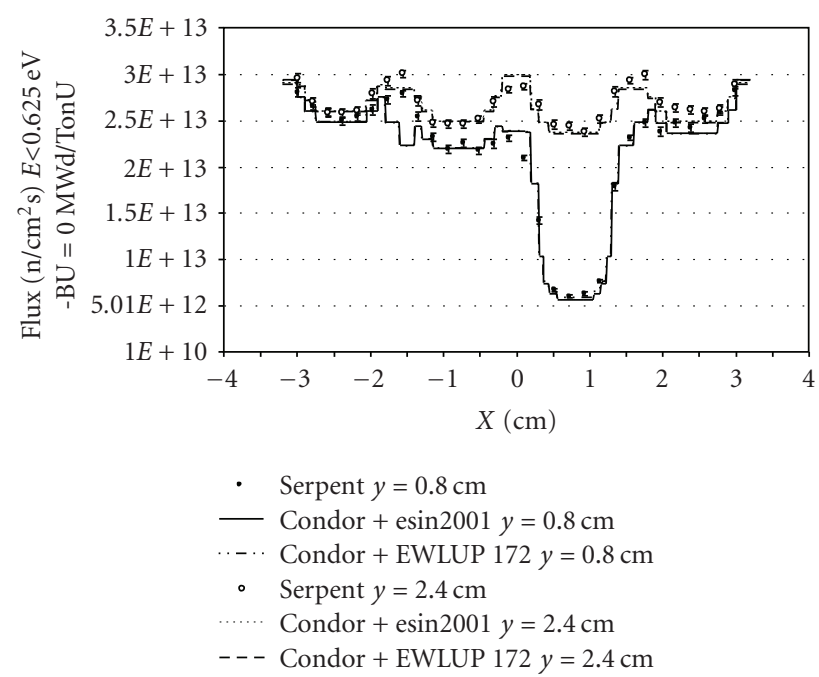

Figure 6: Thermal flux profiles on both models for two different vertical positions $(x, y=0,0$ is the centre of the fuel assembly of Figure 1) for $\mathrm{BU}=0 \mathrm{MWd} /$ ton $\mathrm{U}$.

for two vertical positions (measured in $\mathrm{cm}$ where $x, y=0,0$ is the centre of the fuel assembly of Figure 1). The results are shown on Figures 6 and 7. These results are not reported on the benchmark.

The results obtained for thermal flux profiles show a fairly good agreement between both codes, even when the 


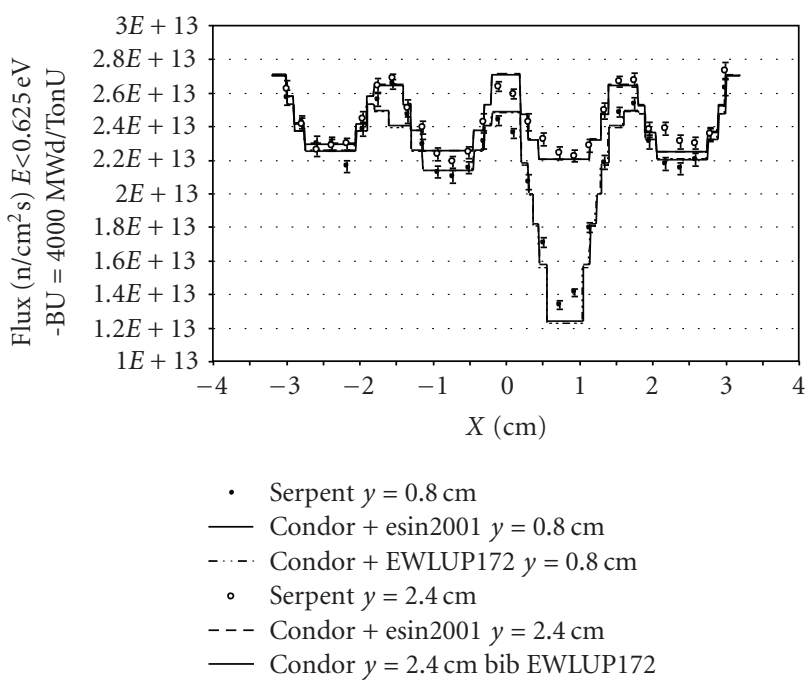

Figure 7: Thermal flux profiles on both models for two different vertical positions $(x, y=0,0$ is the centre of the fuel assembly of Figure 1) for $\mathrm{BU}=4000 \mathrm{MWd} /$ tonU.

fuel assembly is evolved to $4000 \mathrm{MWd} /$ tonU. As far as the averaged zones do in which flux is obtained do not match exactly, slight differences are encountered.

\section{Conclusions}

The results obtained with the Serpent code for this simple benchmark show a fairly good agreement with reported values and with those calculated with INVAP's cell code Condor. The main results regarding reactivity, isotope evolution, and flux profiles show a good agreement, which encourages the future test of the code in other problems, such as more complicated geometries. The next step would be the generation of few group constants to be used in core calculations.

Furthermore, as far as the Serpent code is a celloriented code, the running time is accessible. Nevertheless the running time involved is much bigger than Condor $(2 \mathrm{D}$ collision probability code).

A future work will involve the test of Serpent code in MTR type fuel assemblies to obtain few-group constants generation and perform core calculations.

\section{References}

[1] J. Leppänen, "PSG2 / Serpent-A Continuous-energy Monte Carlo Reactor Physics Burnup Calculation Code v1.1.7".

[2] C. Maeder and P. Wydler, International Comparison Calculations for a BWR Lattice with Adjacent Gadolinium Pins, EIR, Wurenlingen, Switzerland, 1984.

[3] E. Villarino, "Condor Calculation Package," in Proceedings of the PHYSOR 2002, Seoul, South Korea, October 2002.

[4] "Improvements of the WIMS library from ENDF/B-IV DIN/GN/00196".

[5] "WIMS-D library Update Project - IAEA". 

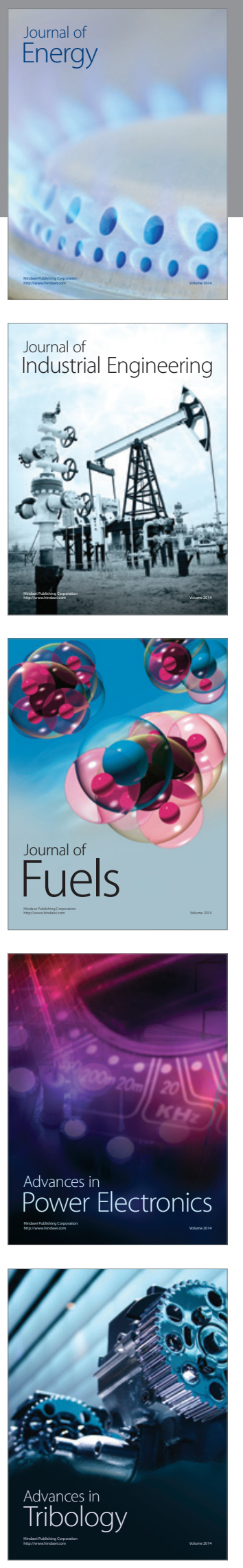
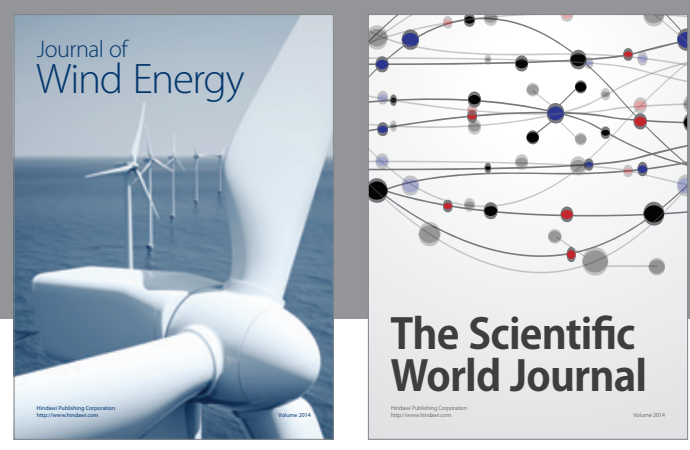

The Scientific World Journal

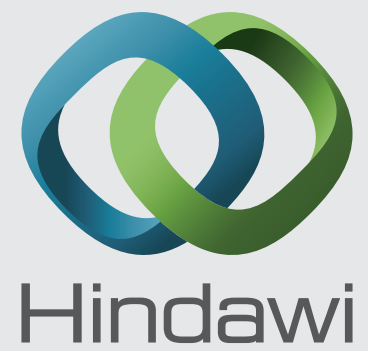

Submit your manuscripts at http://www.hindawi.com
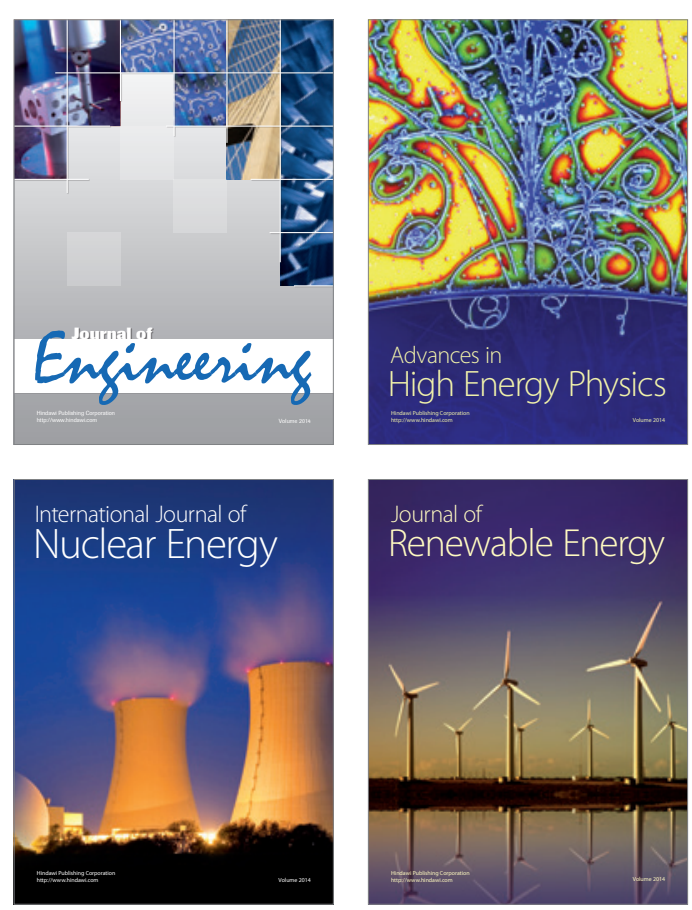

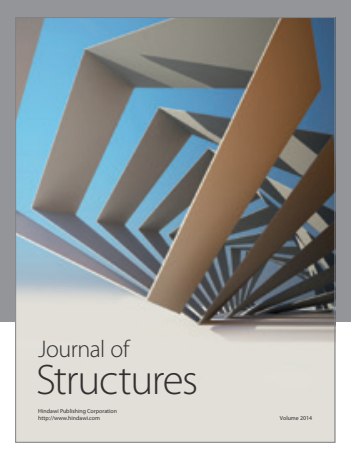

Rotating
Mechinery
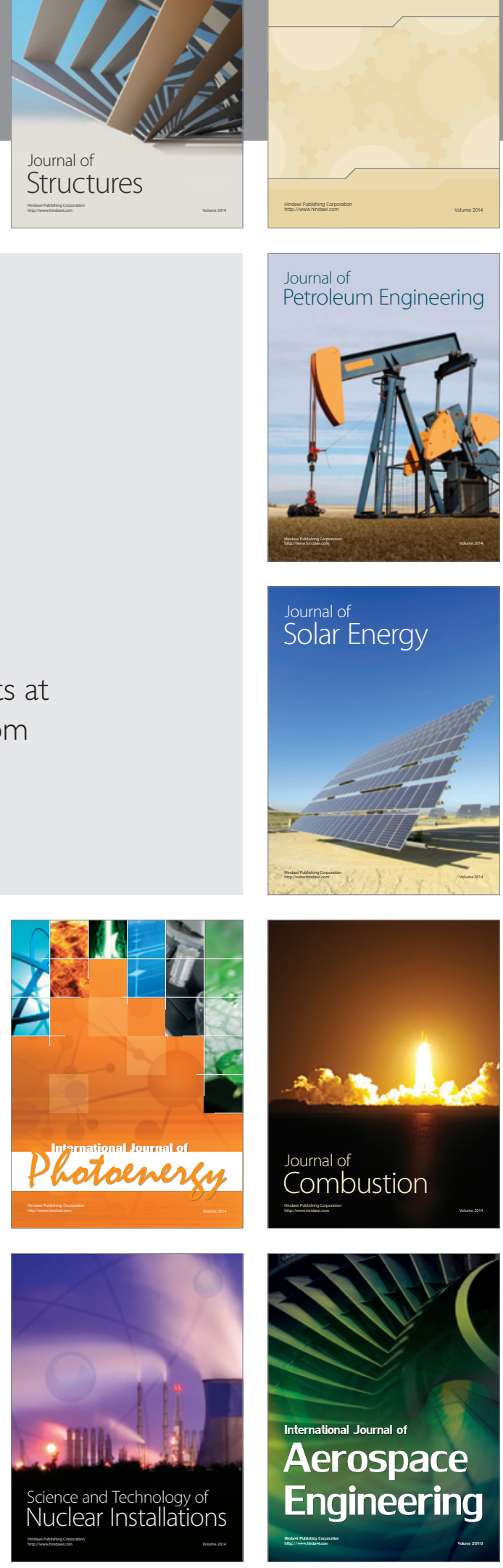